Farum

Sociológico

\section{Forum Sociológico}

Série II

$34 \mid 2019$

Habitação nas áreas urbanas de Lisboa e Porto: Da comunidade aos decisores políticos

\title{
Promoção de Estilos de Vida Saudáveis: Uma Distinção Social?
}

Promotion of Healthy Lifestyles: A Social Distinction?

\section{Pedro Saraiva}

\section{(2) OpenEdition \\ Journals}

Edição electrónica

URL: https://journals.openedition.org/sociologico/4908

DOI: 10.4000/sociologico.4908

ISSN: 2182-7427

Editora

CICS.NOVA - Centro Interdisciplinar de Ciências Sociais da Universidade Nova de Lisboa

Edição impressa

Paginação: 81-88

ISSN: 0872-8380

Refêrencia eletrónica

Pedro Saraiva, «Promoção de Estilos de Vida Saudáveis: Uma Distinção Social?», Forum Sociológico

[Online], 34 | 2019, posto online no dia 19 agosto 2019, consultado o 29 março 2022. URL: http:// journals.openedition.org/sociologico/4908 ; DOl: https://doi.org/10.4000/sociologico.4908 


\title{
PROMOÇÃO DE ESTILOS DE VIDA SAUDÁVEIS: UMA DISTINÇÃO SOCIAL? ${ }^{1}$ PROMOTION OF HEALTHY LIFESTYLES: A SOCIAL DISTINCTION?
}

\author{
Pedro Saraiva \\ Centro de Estudos Sociais da Universidade de Coimbra
}

\begin{abstract}
Resumo
Nas sociedades capitalistas actuais, os estilos de vida saudável, assim como a ideia de "corpo ideal", como sinal desses estilos, são promovidos através de elaboradas estratégias de marketing. Até que ponto se pode falar em distinção social entre classes na promoção destes estilos de vida? Numa breve reflexão, baseada em literatura científica existente nesta área, discute-se a questão da distinção social na promoção de estilos de vida saudável, com especial enfoque na frequência de ginásios.

Num primeiro momento o debate teórico incide sobre as "sociedades de consumo" e a promoção de estilos de vida saudáveis. Num segundo momento, apresentam-se e discutem-se estudos empíricos que mostram como a distinção social neste âmbito é uma realidade e outros que apontam para a massificação dos produtos e serviços associados aos estilos de vida saudáveis, chegando hoje a um grande número de consumidores com recursos culturais ou económicos variáveis.

Conclui-se que a resposta à questão inicial não é unívoca, mas que são notórios os esforços do capitalismo para que a busca por um corpo perfeito e um estilo de vida saudável se difunda por todas as classes sociais.
\end{abstract}

Palavras-chave: consumo, saúde, estilos de vida, distinção social

\begin{abstract}
In today's capitalist societies, healthy lifestyles, as well as the idea of "ideal body" as a sign of these styles, are promoted through elaborate marketing strategies. To what extent can one speak of social distinction between classes in the promotion of these lifestyles? In a brief reflection, based on scientific literature in this area, we discuss the issue of social distinction in promoting healthy lifestyles, with special focus on gymnasium attendance.

At first, the theoretical debate focuses on "consumer societies" and the promotion of healthy lifestyles. In a second moment, empirical studies are presented and discussed that show how the social distinction in this scope is a reality and others that point to the massification of the products and services associated to the healthy lifestyles reaching today a large number of consumers with cultural or economic resources.

It is concluded that the answer to the initial question is not univocal, but that the efforts of Capitalism are notorious so that the search for a perfect body and a healthy lifestyle diffuses through all social classes.
\end{abstract}

Keywords: consumption, health, lifestyles, social distinction

\section{Introdução}

Em pleno século XXI, vivemos rodeados de publicidade que apela ao consumo. Consumo esse que deve ser contínuo e regular no tempo. Com esta publicidade, mostra-se aos consumidores como é importante consumir para se atingir um certo nível de satisfação e de felicidade pessoal. Sem esse consumo, não será possível ser-se feliz e ter-se um estilo de vida condigno.

No entanto, vivemos também em sociedades nas quais se generalizou um discurso, inicialmente 
ligado à medicina, sobre a necessidade de ter estilos de vida saudável, para ajudar na prevenção de doenças e para melhorar a qualidade de vida das pessoas (Crawford, 2006, p. 408). Todavia, este discurso, que era exclusivamente médico, deixou de o ser. Pensando que o capitalismo é um sistema económico que põe tudo o que tenha valor, como por exemplo o dinheiro, a trabalhar por forma a produzir lucro económico (Delacroix, 2007, p. 390), este sistema cria novos consumidores, que se mostram cada vez mais preocupados com a sua saúde.

Quando surgiu, este discurso começou pelo aparecimento de novos produtos alimentares, prometendo contribuir para estes estilos de vida saudável tão difundidos pela medicina. No entanto, começa-se a promover igualmente a prática desportiva como outra forma de ajudar a atingir este tipo de estilo de vida. De tal forma que o capitalismo, através de marcas e empresas privadas, com vista à obtenção de lucro económico, cria formas para que as pessoas possam cada vez mais ter mais acesso a vários equipamentos desportivos (como, por exemplo, roupa desportiva) ou, ainda, ginásios desportivos, com uma expansão crescente em todos os países e com cada vez mais modalidades desportivas variadas para serem praticadas.

Estão reunidas as condições essenciais para que os consumidores se possam tornar mais magros, com corpos invejáveis e com menor risco de doenças, ao mesmo tempo que atingem o desejado nível de satisfação e de felicidade pessoal promovido pelo capitalismo.

No entanto, será que esta promoção de estilos de vida saudável não está a criar diferenças entre classes, nomeadamente, entre uma classe alta, que pode pagar para aceder a esses estilos de vida, e uma classe baixa, com rendimentos baixos e que pode ter dificuldades em aceder a esses mesmos estilos? Este ensaio pretende reflectir e discutir sobre a possível distinção social provocada pela promoção de estilos de vida saudável em sociedades de consumo.

É feita, em primeiro lugar, uma exposição possível sobre o que se entende atualmente por "sociedade de consumo", com os contributos de alguns autores que se debruçaram sobre esta matéria, seguida de uma breve exposição da importância de estilos de vida saudável para a saúde. De seguida, segue-se uma exposição sobre a promoção de estilos de vida saudável nestas sociedades, sobretudo focando a questão das idas ao ginásio. Esta escolha pela questão do exercício físico prende-se pela (suposta) facilidade que os consumidores têm em começar a praticar desporto, com maior ou menor intensidade. Além disso, e focando a questão das idas aos ginásios, estes espaços têm surgido com muita regularidade nas nossas cidades, tornando-se, de forma gradual, cada vez mais indispensáveis na nossa luta contínua por estilos de vida mais saudáveis. Por fim, chega-se à devida reflexão sobre a distinção social através da promoção destes estilos de vida saudável, apresentando as devidas conclusões sobre este ensaio.

\section{A sociedade de consumo nos nossos dias}

Nas sociedades de hoje, o acto de consumo é algo que pode ser visto como sendo natural. Como aponta Barbosa, o acto de consumo é "uma atividade presente em toda e qualquer sociedade humana" (2004, p. 7). Ou como Ryan sugere, o consumo está associado aos actos tomados pelos indivíduos, de forma a colmatar necessidades, com estes actos a serem desempenhados sobretudo na sua vida privada (2007, p. 701).

Como tal, o conceito de "sociedade de consumo" surge como um conceito caracterizador das nossas sociedades em pleno século XXI. Ou como Lipovetski afirma: "A ideia de sociedade de consumo soa agora como uma evidência, aparece como uma das figuras mais emblemáticas da ordem econômica e da vida cotidiana das sociedades contemporâneas" (2006, p. 23). No entanto, definir o que tipicamente se expressa por "sociedade de consumo" não é tarefa fácil, bem pelo contrário (Lipovetski, 2006, p. 8), devido às várias abordagens teóricas que se podem tomar. Pode-se mesmo apresentar outros conceitos semelhantes com o mesmo sentido, como é o caso de Zygmunt Bauman.

Bauman fala-nos de "sociedade de consumidores", que para ele "representa o tipo de sociedade que promove, encoraja ou reforça a escolha de um estilo de vida e uma estratégia existencial consumistas, e rejeita todas as opções culturais alternativas" (2007, p. 71). Esta é uma sociedade em que não há reconhecimento de diferenças de idade ou de género (Bauman, 2007, p. 73). Para o autor, o acto de consumo significa o investimento na afiliação social do próprio consumidor, ou seja, obtêm-se qualidades que ainda não se têm ou melhora as que já se têm (Bauman, 2007, p. 75), o que dessa forma permite sair do constrangimento de classe, na medida em que o consumidor se torna um consumidor autónomo.

Ora, esta ideia de consumidor autónomo vem também ao encontro da ideia de hiperconsumo, de que Lipovetski fala. Ou seja, ao mesmo tempo que ficam para trás os constrangimentos de classe, "os consumidores mostram-se mais imprevisíveis e voláteis, mais à espera de qualidade de vida, de comunicação e de saúde, têm melhores condições de fazer uma escolha entre as diferentes propostas da oferta" (2006, p. 41). O consumo foca-se cada vez mais nos gostos particulares e individuais de cada um, em que se procura maximizar o seu consumo. Mais ainda, se pensarmos que os produtos para 
serem consumidos têm uma curta validade (Ryan, 2007, p. 702).

Para se pensar este mesmo consumo, também é preciso não esquecer o papel importante do marketing, destacado por Jean Baudrillard. Como aponta o autor, e embora o consumo seja cada vez individualizado, as várias publicidades que se podem encontrar em todo o lado criam consensos entre as pessoas por forma a que todos sigam os códigos que estão a emergir (1998, p. 125). Vivemos em sociedades em que se promove um consumo contínuo, esperando sempre que o consumidor aumente mesmo o consumo dos seus produtos favoritos, ou que comece o consumo de outros produtos que ainda não conhece. Associado com o marketing, e além de se criar necessidades, cria-se a esperança, ou seja, ao seguir o discurso das campanhas publicitárias, é possível tornar reais as mensagens veiculadas por estas nas rotinas dos consumidores (Baudrillard, 1998, p. 127).

Embora com diferentes abordagens à actual forma de consumo nos nossos dias, todos os autores convergem no mesmo sentido: As nossas sociedades estão transformadas por forma a consumir de forma regular e contínua no tempo, mas em grandes quantidades. Além disso, o consumo é feito de forma individualizada, fugindo aos constrangimentos de classe, permitindo chegar a um maior número de consumidores. De acrescentar, também, o grande papel do marketing para chegar aos consumidores ou potenciais consumidores. Todavia, em paralelo com este consumo, dá-se cada vez mais importância à promoção de estilos de vida saudáveis. Esse é o seguinte ponto a ser discutido neste ensaio.

\section{Importância de estilos de vida saudáveis para a saúde}

A medicina tem um papel central na regulação da vida social, ao distinguir comportamentos saudáveis e não saudáveis que devem ser seguidos pelos indivíduos (Crawford, 2006, p. 404), chamando a atenção dos indivíduos para a necessidade de se ter uma vida saudável, por forma a evitar doenças, através de discursos para a promoção de estilos de vida saudáveis.

Estes discursos surgem na medicina, em face do aumento do número de casos de obesidade, um pouco por todo o mundo. Surgem sobretudo como uma necessidade de combater este problema em particular, ao mesmo tempo que se previnem várias doenças associadas à obesidade e se promove uma melhor qualidade de vida.

No caso da Organização Mundial de Saúde, tem havido uma preocupação em incentivar os seus Estados-membros a delinearem e aplicarem estratégias de promoção de estilos de vida saudável, através da promoção de atividade física
(Organização Mundial de Saúde, 2018, pp. 1- 2). A OMS chega mesmo a publicar, nos seus relatórios, recomendações sobre como a actividade física deve ser executada, por grupos de idade (Organização Mundial de Saúde, 2018, p. 4; 2017, p. 1). A nível nacional e regional, também tem sido adoptado um conjunto crescente de iniciativas, com base nas indicações da OMS (Fortune et al., 2018, p. 623).

Como afirma Costa, "tudo aponta para a falta de hábitos saudáveis e de um estilo de vida activo que permitam alcançar o bem-estar, recuperando a velha máxima mente sã em corpo são [itálico do autor]" (2008, p. 1). O que se confirma pelos dados mais recentes num estudo realizado em Portugal ${ }^{2}$. Tendo em conta estes discursos, o conceito de "saúde" é descrito segundo as condições e, possibilidades para se atingir uma vida saudável, através de várias soluções (Crawford, 2006, p. 404), e, por isso mesmo, é veiculada a necessidade de seguir estilos de vida saudável. Este conceito de "estilos de vida saudável" tem várias vertentes possíveis, mas, seguindo o foco deste artigo, uma dessas vertentes prende-se com a prática de exercício físico.

Dessa forma, este estilo de vida encontra-se associado ao consumo extensivo de produtos e de serviços, como roupa e calçado desportivo, dietas, idas ao ginásio, entre outros (Cockerham, 2007, p. 2061). Como aponta Assumpção et al., "sustenta-se a hipótese da necessidade de se promoverem mudanças no seu estilo de vida, levando-o a incorporar a prática de atividades físicas ao seu cotidiano" (2002, p. 1). Esta ideia prende-se com o discurso da medicina que "associa o estilo de vida saudável ao hábito da prática de atividades físicas e, consequentemente, a melhores padrões de saúde e qualidade de vida" (Assumpção et al., 2002, p. 2). Dessa forma, e mesmo com restrições de tempo, a actividade física deve ser incorporada como uma actividade do quotidiano de cada um de nós (Beaudoin, Fernandez, Wall \& Farley, 2007, p. 2 ). Os próprios meios de comunicação social têm desempenhado um papel fundamental na divulgação da necessidade de hábitos mais saudáveis, em prol da saúde (Beaudoin et al., 2007, p. 5).

Verifica-se por isso que é necessário promover estilos de vida saudável, que ajudam a combater doenças que diminuem a qualidade de vida das pessoas. Dessa forma, os meios de comunicação social, mas também o próprio marketing, têm um papel fundamental na promoção desses mesmos estilos de vida, como apontam Dixon et al., que defendem que são feitas campanhas por forma a provocar mudanças de comportamento associadas à saúde, incentivando a comportamentos mais saudáveis (2015, p. 1). Como aponta Crawford, uma vida saudável está reduzida a apenas um problema de saúde (1980, p. 381), e, com a adopção destes estilos de vida, este problema será resolvido. 
Tendo em conta todos estes benefícios para a saúde, através da adopção de estilos de vida saudáveis, com a prática de exercício físico de forma regular, cria-se a necessidade de alargar estas práticas ao maior número de pessoas possível. Perante essa necessidade e graças ao papel que o marketing tem no nosso consumo diário, o capitalismo aproveita-se desta situação para promover estes estilos de vida, através do consumo de produtos relacionados com a prática desportiva. Situação essa que será discutida no ponto seguinte, focando particularmente a questão da prática desportiva, no que diz respeito às idas ao ginásio.

\section{Promoção de estilos de vida saudáveis nas nossas sociedades}

Em face da necessidade de promover estilos de vida saudável, para prevenir o aparecimento de doenças, que ameaçam a qualidade de vida das pessoas, o capitalismo surge como o principal aliado da medicina para a promoção e divulgação destes discursos. E faz essa promoção de forma engenhosa, adaptando-se à realidade que surge com o aparecimento destes discursos, aproveitando por exemplo o aumento constante da cultura desportiva da população em geral (Barbosa, 2014, p. 63). Para Rojas, ir ao ginásio é um mero acto de consumismo (2016, p. 277). Verifica-se mesmo o crescimento de uma panóplia de equipamentos (desportivos e não-desportivos) ao dispor do consumidor, como as lojas de produtos naturais, espaços com aparelhos de musculação, salas para aulas de body-pump, ginástica localizada, entre outros (Costa, 2008, p. 1).

Esta também é uma forma de permitir a satisfação do lazer, vista como da "maior importância para o bem-estar das pessoas enquanto indivíduos ou sociedades" (Elias \& Dunning, 1985, p. 106). Com toda a variedade de actividades possíveis de serem realizadas, estas actividades são idealizadas como "votadas ao lazer, no sentido de uma ocupação escolhida livremente e não renumerada - escolhida, antes de tudo, porque é agradável para si mesmo" (Elias \& Dunning, 1985, p. 107). Como defende Lipovetski, as pessoas encontram "o caminho da realização pessoal mais nos prazeres do tempo livre e da vida relacional que no ativismo profissional" (2006, p. 265).

Percebe-se desta forma que é possível ter actividades físicas, associando a ideia de lazer com a ideia de promover um estilo de vida saudável. No entanto, o capitalismo aproveita esta situação para atingir outros objectivos, nomeadamente ao criar uma preocupação em torno dos corpos dos consumidores, com o surgimento de novos produtos e de novas necessidades, tornando-os cada vez mais "um produto privilegiado da lógica industrial" (Assumpção et al., 2002, p. 9).
Criou-se, por isso, a necessidade de os consumidores cuidarem a sua imagem corporal. Ou seja, o capitalismo toldou os consumidores por forma a que estes olhem o seu corpo como uma imagem a manter ou a melhorar, se for caso disso. No estudo realizado por Rojas, aponta-se claramente as idas aos ginásios como forma de as pessoas quererem cada vez mais ter um corpo saudável, livre de gorduras, associado à ideia de ser belo, enérgico e jovem (2016, p. 293). Os próprios meios de comunicação social desempenham um papel fundamental neste caso: "Assiste-se hoje, na televisão, nos jornais e em revistas, a uma verdadeira veneração pelo corpo esculpido, belo e sedutor. Este padrão corporal é produzido e difundido pelos veículos de comunicação. Valoriza-se a aparência, a sedução, o fascínio" (Assumpção et al., 2002, p. 9). O capitalismo criou a ideia do "corpo ideal", sendo necessário passar por determinados processos para atingir aquele mesmo corpo. Há mesmo uma medicalização do consumo, em que se pode recorrer a vários tratamentos médicos para atingir o corpo considerado "ideal", se tal for necessário.

No caso da prática desportiva, nomeadamente as idas ao ginásio, o que era primeiro visto como uma actividade de lazer, é visto agora como uma actividade altamente medicalizada, em que se procura atingir o corpo perfeito, com produtos que permitem perder peso, que aumentam o desempenho desportivo e conservam a juventude, prometendo ajudar a ultrapassar as dificuldades sociais dos indivíduos (Lipovetski, 2006, p. 280). No caso das mulheres, há igualmente a ideia do corpo magro e jovem, no qual a "norma tirânica da magreza leva as mulheres, em particular, a controlar permanentemente o peso e alimentação, a querer remodelar a silhueta a ponto de fazê-las parecer 'escravas da aparência'" (Lipovetski, 2006, p. 276). Há mesmo dados para o caso de Portugal que apontam para esse sentido ${ }^{3}$.

Como observa Baudrillard, o corpo é comparado a um território "virgem" que é colonizado, no qual se vão desenvolver sinais visíveis de felicidade, de saúde e de beleza (1998, p. 131). O corpo é reapropriado por forma a cumprir os objectivos do capitalismo, investindo-se nele por forma a obter uma produção própria (Baudrillard, 1998). Além disso, o trabalho que é feito com o corpo é visto como essencial para a identidade pessoal de cada um de nós, mas também como uma forma de atingir status social (Wachs, 2007, p. 710).

Em face da necessidade de promoção de estilos de vida saudáveis, e como forma de contrariar o alastramento de doenças e de forma a garantir a qualidade de vida dos consumidores, cria-se um "corpo exemplo", no qual se mostra que para atingir a felicidade é preciso trabalhar cumprindo certas normas e consumindo determinados produtos. Mas 
os consumidores deixam de controlar o seu corpo, que passa a ser controlado pelo capitalismo, que molda os corpos como bem entende.

No fundo, o capitalismo criou a necessidade de cuidado da nossa imagem, porque essa imagem reflecte o que são os consumidores enquanto pessoas. Para se atingir o nível de satisfação e felicidade pessoal que o capitalismo promete, é preciso transformar e cuidar do corpo. Só assim se pode atingir a ambicionada felicidade, tão vastamente prometida. Como afirma Assumpção et al.: "A lógica de mercado determina o estilo de vida considerado 'saudável' bem como os padrões de comportamento e os modelos de corpo que devem ser vendidos e consumidos pelas diferentes classes sociais" (2002, p. 9). Como aponta a citação ("vendidos e consumidos pelas diferentes classes sociais"), pressupõe que poderá haver consumos diferenciados para diferentes classes sociais. Dessa forma, será que todos os consumidores poderão ter acesso a esta felicidade pessoal, através da transformação corporal?

Para poder praticar exercício físico num ginásio de forma regular, por forma a atingir o "corpo ideal", é necessário um grande investimento financeiro por parte dos consumidores. Investimento não só nas mensalidades do ginásio, como também no equipamento desportivo, nos suplementos desportivos, entre outros. Investimentos esses que podem não estar acessíveis a todos. Esta é a discussão que será realizada de seguida.

\section{Promoção de distinção social?}

Devido ao grande investimento financeiro necessário para atingir a transformação corporal necessária para conseguir a tão desejada felicidade, promovida pelo capitalismo, nem todos os consumidores poderão ter os recursos financeiros para atingir isto. Será que se pode falar numa distinção entre uma classe alta, com elevados recursos culturais e financeiros que permitem praticar exercício físico num ginásio e fazer outros investimentos associados, por forma a atingir o "corpo ideal", e uma classe baixa, que não dispõe dos mesmos recursos, e que por isso não tem possibilidade de procurar atingir esse mesmo "corpo"? Esta é uma pergunta que, à partida, parece fácil de responder.

No entanto, o que se pode entender por distinção? Como é que ela se pode manifestar? Holt apresenta os seus argumentos, afirmando que tudo aquilo que as pessoas consomem expressa gostos, ou seja, os gostos que as pessoas têm agem como mecanismos de reprodução e distinção social, reproduzindo diferenças entre as várias classes sociais (2007, p. 1189).

Pierre Bourdieu, na sua obra $A$ Distinção, defende que o conhecimento que temos do mundo social se serve de esquemas que permitem classifi- cações, ou seja, "esquemas históricos de percepção e apreciação que são o produto da divisão objetiva em classes (faixas etárias, classes sexuais, classes sociais) e que funcionam aquém da consciência e do discurso" (2007, p. 436). Leão et al., numa pesquisa no Brasil, identificaram que "parte significativa do significado atribuído às marcas pelos consumidores passa pela compreensão delas como signos estatutários; uma forma de estabelecer hierarquia entre as pessoas" (2014, p. 89). Para os autores, é mesmo uma "estratégia de manutenção de poder daquelas dominantes sobre as demais" (Leão et al., 2014, p. 90).

Podemos por isso definir o conceito de distinção social, como apresentado por Williams ${ }^{4}$, como um fenómeno social que, baseado em normas sociais vigentes, promove a diferenciação entre os indivíduos, através de vários critérios, como a idade, o sexo, a religião, entre outros (2007, p. 4406). Pode-se acrescentar outros critérios, como os gostos, o que cada um come, o que cada um veste, onde cada um gosta de relaxar (Giddens, 2006, p. 322). Todos estes critérios promovem distinção entre os indivíduos e, por isso mesmo, distinção entre classes sociais.

Se pensarmos que o consumo de produtos e serviços é criado por forma a que seja global, pode-se mesmo falar em dois níveis distintos de consumo, sendo que, por um lado, há um consumo que permite atingir prestígio e poder, e outro que corresponde a necessidades sociais (Ryan, 2007, p. 702).

Ora, se pensarmos que a classe baixa tem uma preocupação em suprimir estas "necessidades sociais", que se traduzem em necessidades básicas, como alimentação, alojamento, saúde, entre outros exemplos, poderá apontar-se então para uma distinção entre uma classe que procura competir pelo poder e status, que se materializa através de um consumo individualizado (elementos de classe alta), e uma classe que não procura poder, mas sim satisfazer necessidades básicas diárias, que acabam por ser comuns entre os seus membros (elementos de classe baixa). No caso dos elementos da classe alta, poder-se-á afirmar que o consumo surge como uma necessidade de aumentar o seu status social, tendo presente a necessidade de se distinguir de outros actores sociais (Schor, 2007, p. 683).

Cockerham aponta igualmente neste sentido, completando as ideias dos autores anteriores, ao afirmar que os estilos de vida são baseados nos consumos realizados, uma vez que o consumo de determinados produtos ou serviços mostram o status dos seus consumidores (2007, p. 2061).

Poder-se-ia apontar claramente que sim. Existe uma distinção social entre a classe alta e a classe baixa sobre o acesso a estilos de vida saudáveis e, consequentemente, ao "corpo ideal" promovido pelo capitalismo. Um estudo realizado por Bakcken- 
-Ulseth \& Seippel, num ginásio, aponta claramente o rendimento como um factor de distinção social entre as pessoas que frequentam o ginásio estudado (2011, p. 14). No entanto, como ambas as autoras também reconhecem, existem muitos outros factores que desconhecem e que podem ou não causar distinção social (Bakcken-Ulseth \& Seippel, 2011, p. 14). Num outro estudo realizado sobre a ida aos ginásios, Rojas afirma que a ida ao ginásio permite desenvolver e reforçar a identidade de quem o frequenta (2016, p. 294). Ora, diferentes utilizadores de diferentes classes vão moldar a sua identidade, quer pertençam à classe alta, quer à classe baixa.

Mas, por outro lado, não se pode afirmar totalmente que existe distinção social entre classes aquando do momento de frequentar ginásios e de procurar o "corpo ideal". Existem outros aspetos a ter em conta e que devem também ser alvo de reflexão e que aqui não são discutidos. Um exemplo relevante prende-se com as dietas alimentares, complementadas por suplementos alimentares, que são cada vez mais usadas por quem pretende perder peso e atingir o "corpo ideal".

Pode-se até apontar que estes mesmos estilos de vida foram massificados pelo capitalismo por forma a chegar a um maior número de consumidores, independentemente dos recursos culturais ou financeiros de que possam dispor. O exemplo que se pode dar é a massificação do uso de roupa e calçado desportivo. Inicialmente, este tipo de roupa e calçado era dispendioso e não era acessível a todas as pessoas. No entanto, com o aparecimento de grandes superfícies comerciais dedicadas à promoção de desporto, um pouco por todo o lado e com preços baixos, torna-se acessível a todo o tipo de consumidores, podendo-se mesmo falar de uma massificação deste tipo de equipamento desportivo. Tendo acesso a este tipo de roupa, essencial para a prática de exercício físico em ginásios, o acesso a estes espaços torna-se igualmente mais fácil.

Vistos como locais de estabelecimento de laços sociais entre as pessoas, também eram vistos como locais onde as pessoas que tivessem maiores recursos culturais e financeiros se poderiam encontrar, ao mesmo tempo que iriam transformar o corpo por forma a atingir o corpo saudável, tão badalado pelo capitalismo. No entanto, as idas ao ginásio também se massificaram, com o aparecimento contínuo de novos ginásios, com preços cada vez mais acessíveis, para atingir um maior número de consumidores possível, verificando-se mesmo um aumento de número de utilizadores destes espaços ${ }^{5}$.

Acrescenta-se igualmente o facto de os ginásios terem várias modalidades desportivas, praticadas através de aulas de grupo com acompanhamento de instrutores personalizados, o que permite que estes novos consumidores praticamente "se sintam em casa". Associado à prática de desporto em ginásio, facilita também o aparecimento de grandes eventos como o Portugal $\mathrm{Fit}^{6}$, considerado o maior evento de fitness e de promoção de estilos de vida saudáveis em Portugal e realizado uma vez por ano, que permite divulgar a mensagem de que todos os consumidores, independentemente dos recursos de que disponham, podem e sobretudo devem frequentar os ginásios, para bem da sua saúde.

Para Lipovetski (2006), percebe-se que a distinção social, no que diz respeito ao consumo, é inexistente:

"Não é mais a oposição entre a elite dos dominantes e a massa dos dominados, nem aquela entre as diferentes frações de classe que organiza a ordem do consumo, mas o 'sempre mais' e o zapping generalizado, as bulimias exponenciais de cuidados, de comunicações e de evasões renovadas." (p. 43)

\section{Conclusão}

Em face dos vários problemas de saúde ligados aos maus hábitos alimentares, mas também ligados ao sedentarismo e à obesidade, um pouco por todo o mundo, têm sido difundidos discursos para a necessidade de adopção de estilos de vida saudáveis, que incluam o consumo de alimentos considerados saudáveis e a prática contínua de exercício físico. Estes discursos são carregados de lógicas que pressupõem que a adopção destes estilos de vida permite a melhoria da qualidade de vida das pessoas, e a consequente melhoria da felicidade pessoal.

Focando a atenção na prática desportiva em ginásios, o capitalismo, tal como em outras fases anteriores da História, conseguiu adaptar-se a estes discursos, criando mecanismos próprios para aumentar o consumo de produtos e serviços relacionados com a adopção e manutenção de estilos de vida saudável, apostando, por exemplo, na massificação de espaços desportivos, como os ginásios, e, na consequente redução das mensalidades ou novas formas de pagamento destas mesmas idas (pagamento semanal em vez de pagamento mensal).

Aproveitando o facto de o desporto ser visto como uma actividade de lazer e de prática saudável, o capitalismo aproveitou bem este facto para se expandir através desta prática, chegando às pessoas.

Espaços como ginásios e locais semelhantes são vistos como locais de consumo, onde cada consumidor se cria ou se reinventa a si mesmo, marcando a existência de uma identidade, com marcadores ligados à etnicidade e género, ligados a estilos específicos de consumo (Rojas, 2016, p. 294).

Associado a esta prática desportiva, percebe-se que as pessoas têm vindo a procurar o "corpo ideal", com determinadas características, que iria 
permitir aos consumidores atingir um alto nível de satisfação e felicidade pessoal, conforme veicula o capitalismo. Sobretudo se se tiver em conta a promoção de uma cultura visual de âmbito público (como, por exemplo, o cinema), que alerta para a importância da aparência externa, mas sobretudo para os cuidados com o corpo (Wachs, 2007, p. 709).

No entanto, em face deste contexto, a reflexão principal foi sobre a possível distinção social entre classes no que diz respeito ao acesso a estes mesmos estilos de vida. Apesar de os autores aqui citados, e os estudos realizados nos seus países, apontarem para a existência de distinção social entre quem pode atingir ou não o "corpo ideal", não se poderá dizer que existe uma clara distinção social, mas também não se pode afirmar que esta não existe.

Embora se possa afirmar que o capitalismo tem vindo a procurar formas de se adaptar a estes novos estilos de vida, são necessários estudos que comprovem a existência, ou não, de distinção social, no momento da busca pelo "corpo ideal".

Pode-se, no entanto, afirmar que o capitalismo molda estas mesmas pessoas, independentemente da classe social a que pertencem, de forma que sigam as normas que impõe, consumindo aquilo que o capitalismo quer, tentando eliminar a distinção social que possa existir entre as pessoas. Todos os mecanismos de distinção que possam existir poderão ser esbatidos por forma a que desapareçam, criando a ilusão de que são consumidores livres e conscientes.

\section{Notas}

1 Este texto foi realizado no âmbito de uma Bolsa de Doutoramento da Fundação para a Ciência e a Tecnologia (ref. a SFRH/BD/137480/2018), financiada pelo Fundo Social Europeu e por fundos nacionais do Ministério de Ciência, Tecnologia e Ensino Superior de Portugal.

2 Para mais informações, consultar a notícia do Diário de Notícias: https://www.dn.pt/sociedade/interior/ portugueses-estao-a-beber-e-a-fumar-menos-mas-sao-mais-gordos-e-inativos-8940036.html

3 Para mais informações, consultar o estudo realizado pela Marktest: http://www.marktest.com/wap/a/n/id 21d1. aspx

4 Apesar de ser feita referência ao conceito de "distância social", é apenas uma outra forma de fazer referência ao conceito de "distinção social", de uma maneira ou de outra, referem-se sempre ao mesmo fenómeno social.

5 Para dados em concreto, consultar o estudo realizado pela Marktest: http://www.marktest.com/wap/a/n/id 211a. aspx

6 Para mais informações sobre este evento, consultar: http://arena.altice.pt/agenda/portugalfit_pt/2670/ e http://www.portugalfit.pt/

\section{Referências bibliográficas}

Assumpção, L. O. T., Morais, P. P., \& Fontoura, H. (2002). Relação entre atividade física, saúde e qualidade de vida. Notas introdutórias. Revista Digital Buenos Aires, 52(8). Disponível em http://www.efdeportes. com/efd52/saude.htm

Bakcken-Ulseth, A. L., \& Seippel, O. (2011). Fitness, Class and Culture: Social Inequality in Fitness. Nordic Sport Science Forum, 1-17. Disponível em http://idrottsforum.org/articles/ulseth_seippel/ ulseth_seippel111123.pdf

Barbosa, L. (2004). Sociedade de Consumo. Rio de Janeiro, Brasil: Jorge Zahar Ed.

Barbosa, S. (2014). Relatório de Atividade Profissional no Forlife, Desporto e Bem-Estar. (Relatório de Mestrado, Instituto Politécnico da Guarda.) Disponível em http://bdigital.ipg.pt/dspace/ bitstream/10314/2237/1/MKTC_Sandra\%20 Barbosa.pdf

Baudrillard, J. (1998). The Consumer Society. Londres, Inglaterra: SAGE Publications Ltd.

Bauman, Z. (2007). Vida para Consumo. A transformação das pessoas em mercadoria. Rio de Janeiro, Brasil: Jorge Zahar Ed.

Beaudoin, C. E., Fernandez, C., Wall, J. L., \& Farley, T. A. (2007). Promoting Healthy Eating and Physical Activity. Short-Term Effects of a Mass Media Campaign. American Journal of Preventive Medicine, 32(3), 217-223. Disponível em http://www.sciencedirect.com/science/article/pii/ S0749379706004934

Bourdieu, P. (2007). A Distinção. Porto Alegre, Brasil: Zouk.

Cockerham, W. C. (2007). Health Lifestyle. In G. Ritzer (Ed.), The Blackwell Encyclopedia of Sociology (pp. 2061-2063). Malden, EUA: Blackwell Publishing, Ltd.

Costa, M. (2008). Valor da Marca no Fitness: estudo da Imagem e das Associações à Marca na Lealdade. (Dissertação de Mestrado, Universidade Técnica de Lisboa.) Disponível em https://repositorio. iscte-iul.pt/bitstream/10071/1691/1/Valor_da Marca_no_Fitness_MarisaCosta.pdf

Crawford, R. (1980). Healthism and The Medicalization of Everyday Life. International Journal of Health Services, 10(3), 365-388. Disponível em https:// journals.sagepub.com/doi/abs/10.2190/3H2H3XJN-3KAY-G9NY?journalCode = joha

Crawford, R. (2006). Health as a meaningful social practice. Health: An Interdisciplinary Journal for the Social Study of Health, Illness and Medicine, 10(4), 401-420. Disponível em http://journals. sagepub.com/doi/abs/10.1177/1363459306067 310?journalCode $=$ heaa

Delacroix, J. (2007). Capitalism. In G. Ritzer (Ed.), The Blackwell Encyclopedia of Sociology (pp. 390-395). Malden, EUA: Blackwell Publishing, Ltd.

Dixon, H., Scully, M., Cotter, T., Maloney, S., \& Wakefield, M. (2015). Healthy weight and lifestyle advertise- 
ments: an assessment of their persuasive potential. Health Education Research, 30(4), 569-579. Disponível em https://academic.oup.com/her/ article-lookup/doi/10.1093/her/cyv031

Elias, N., \& Dunning, E. (1985). A Busca da Excitação. Lisboa, Portugal: Difel.

Fortune, K., Becerra-Posada, F., Buss, P., Galvão, L. A. C., Contreras, A., Murphy, M., Rogger, C., Keahon, G. E., \& de Francisco, A. (2018). Health promotion and the agenda for sustainable development, WHO Region of the Americas. Bulletin of the World Health Organization, 96, 621-626. Disponivel em http://www.who.int/bulletin/volumes/96/9/17-204404.pdf.

Giddens, A. (2006). Sociology (Fifth Edition). Cambridge, Inglaterra: Polity Press.

Holt, D. B. (2007). Distinction. In G. Ritzer (Ed.), The Blackwell Encyclopedia of Sociology (pp. 11891191). Malden, EUA: Blackwell Publishing, Ltd.

Leão, A., Mello, S., \& Gaião, B. (2014). Uso das Marcas na Vida Cotidiana como Busca por Distinção Social. Organizações em contexto, 10(20), 85-116. Disponível em http://dx.doi.org/10.15603/19828756/roc.v10n20p85-116

Lipovetski, G. (2006). A Felicidade Paradoxal. Ensaio sobre a felicidade de hiperconsumo. São Paulo, Brasil: Companhia das Letras.

Organização Mundial de Saúde (2018). Status report on "PHYSICAL ACTIVITY and HEALTH in the South-East Asia Region". Nova Deli, Índia: Gabinete Regional para o Leste e Sul da Ásia da Organização Mundial de Saúde. Disponível em http://apps.who.int/iris/ bitstream/handle/10665/274308/9789290226697-eng.pdf?sequence $=1$ \&isAllowed $=y$

Organização Mundial de Saúde (2017). An effective approach to early action on noncommunicable disease risk factors. Genebra, Suíça: Sede geral da Organização Mundial de Saúde. Disponível em http://apps.who.int/iris/bitstream/handle/10665/255625/WHO-NMH-PND-17.3-eng. pdf? sequence $=1$ \&isAllowed $=\mathrm{y}$

Rojas, A. S. (2016). I'm super-setting my life! An ethnographic comparative analysis of the growth of the gym market. Sport Science Review, 35(5-6), 321-344. Disponível em https://www.degruyter. com/view/j/ssr.2016.25.issue-5-6/ssr-2016-0015/ ssr-2016-0015.xml

Ryan, M. T. (2007). Consumption. In G. Ritzer (Ed.), The Blackwell Encyclopedia of Sociology (pp. 701-705). Malden, EUA: Blackwell Publishing, Ltd.

Schor, J. B. (2007). Conspicuous Consumption. In G. Ritzer (Ed.), The Blackwell Encyclopedia of Sociology (pp. 681-686). Malden, EUA: Blackwell Publishing, Ltd.

Wachs, F. L. (2007). Consumption And The Body. In G. Ritzer (Ed.), The Blackwell Encyclopedia of Sociology (pp. 709-712). Malden, EUA: Blackwell Publishing, Ltd.

Williams, J. E. (2007). Social Distance. In G. Ritzer (Ed.) The Blackwell Encyclopedia of Sociology (pp. 44064407). Malden, EUA: Blackwell Publishing, Ltd.

Recebido a 25/06/2018. Aceite para publicação a 29/11/2018

Pedro Saraiva (pdgs@outlook.pt). Centro de Estudos Sociais da Universidade de Coimbra - Colégio de S. Jerónimo, Apartado 3087, 3000-995 Coimbra, Portugal 